\title{
The utilization of formal and informal home care by older patients with cancer: a Belgian cohort study with two control groups
}

Abdelbari Baitar ${ }^{1 *}$, Frank Buntinx ${ }^{2,3}$, Tine De Burghgraeve ${ }^{2}$, Laura Deckx ${ }^{4}$, Paul Bulens ${ }^{5}$, Hans Wildiers ${ }^{6}$ and Marjan van den Akker $^{2,3}$

\begin{abstract}
Background: The purpose of this paper is to analyse the utilization of formal and informal home care among older patients with cancer (OCP) and to compare this with middle-aged patients with cancer (MCP) and older patients without cancer (ONC). Additionally, we examined predictors of transitions towards formal care one year after a cancer diagnosis.
\end{abstract}

Methods: OCP and MCP had to be recruited within three months after a cancer diagnosis and have an estimated life expectancy over six months. ONC consisted of patients without known cancer, seen by the general practitioner. Formal and informal care were compared between the patient groups at baseline, i.e. shortly after a cancer diagnosis and changes in care were studied after one year.

Results: A total of 844 patients were evaluable for formal care at baseline and 469 patients (56\%) at follow-up. At baseline, about half of older adults and 18\% of MCP used formal care, while about $85 \%$ of cancer patients and $57 \%$ ONC used informal care. Formal care increased for all groups after one year though not significantly in OCP. The amount of informal care only changed in MCP which decreased after one year. Cancer-related factors and changes in need factors predict a transition towards formal care after a cancer diagnosis.

Conclusions: A cancer diagnosis has a different impact on the use of formal and informal care than ageing as such. The first year after a cancer diagnosis is an important time to follow-up on the patients' needs for home care.

Keywords: Formal care, Informal care, Home care, Cancer, Older patients

\section{Background}

The increasing population of older people and changes in health policy have resulted in a shift from institutional care to home care. It is obvious that functional status plays an important role in the use of professional home care. Therefore, in Belgium and other countries planning and financing of both home nursing and nursing homes are largely based on levels of functioning [1]. Other factors known to be associated with professional home care use include age, gender, educational level, marital status, and informal care [2-5]. Most of this evidence was based on

\footnotetext{
* Correspondence: Abdelbari.baitar@zna.be

'Department of Oncology, ZNA Middelheim, Antwerp, Belgium

Full list of author information is available at the end of the article
}

cross-sectional analyses comparing older people already using professional home care with non-users. Kempen et al. specifically compared older people who started to use professional home care to matched non-users which is more appropriate to understand factors that explain the use of professional home care [2]. Geerlings et al. focused on the process of becoming a user of informal and professional home care by studying transitions in the use of care based on longitudinal data in the Netherlands [6]. More recent studies, based on the Survey of Health, Ageing and Retirement in Europe (SHARE) data, showed crossnational differences in the dynamics of care between various European countries [7-9]. In the present study, we focused on a specific population, Flemish older patients 
with cancer (OCP). The rising population of older people is accompanied by an increase of cancer prevalence rates. A diagnosis of cancer and subsequent treatment can have a substantial effect on the well-being of patients and their need for home care. As shown in our recent work, patients with cancer have increased levels of depression, loneliness, and increasing difficulties in cognitive functioning over the course of one year [10,11]. In light of this, we expect to see significant transitions in care after a diagnosis of cancer. The purpose of this paper is to analyse the utilization of formal and informal home care among OCP shortly after diagnosis and to examine changes after one year. The OCP will be compared to two control groups, a group of middle-aged patients with cancer (MCP) and a group of older primary care patients without cancer (ONC). A second goal is to examine predictors of transitions from no formal care to formal care following a cancer diagnosis.

\section{Methods}

\section{Study design and population}

This analysis was performed on baseline and one-year follow-up data from the Klimop study, which is an ongoing study in Belgium and the Netherlands on the impact of cancer, aging, and their interaction on the well-being of OCP. For this purpose, OCP are compared with $\mathrm{MCP}$ (aging effect) and with ONC (diagnosis effect). The same design was used for the current analysis on home care, however based on our results it sometimes made more sense to compare all patients with cancer to $\mathrm{ONC}$ in the discussion section. Full details of the Klimop study have been described elsewhere [12]. In short, OCP ( $\geq 70$ years), MCP (50-69 years), and ONC ( $\geq 70$ years) are longitudinally compared for different measures of well-being. The group of cancer patients consisted of patients with breast, gastro-intestinal, and lung cancer. Patients had to be recruited within three months after a cancer diagnosis and had to have an estimated life expectancy of more than six months. Data have been collected through personal interviews at baseline (T0), after one year (T1), and subsequently every two years. The analysis for this paper was restricted to patients living at home and who were recruited in Belgium only, given the different homecare system in the Netherlands.

\section{Measurements \\ Formal care}

Professional home care or formal care was dichotomized in 'users' and 'non-users'. Users were defined in this study as having received help from at least one of the following paid professionals in the last three months: home nurse, home help services, physiotherapist, meals on wheels, adult day care, and cleaning help. Formal care was only recorded if the participants had at least five contacts in the last three months prior to the interview in order to avoid the measurement of sporadic use and to be able to evaluate recent use.

\section{Informal care}

Participants were asked to indicate who cared for them, apart from professional help. This could be a partner, children, other relatives, friends, neighbours, or volunteers. Informal care was defined as help provided by any of them (partners, children, other relatives, friends, neighbours, or volunteers).

\section{Independent variables}

Consistent with previous research on home care, we used Andersen and Newman's behavioural model as a theoretical framework to order variables at the individual level in predisposing, enabling and need factors to predict the utilization of formal care [13]. Predisposing variables were: age, gender, marital status, and educational level. We considered the availability of informal care as an enabling variable. As need factors we considered functional status, depression, loneliness, fatigue, cognitive status, nutrition, polypharmacy and comorbidity. Since the focus of this study is on cancer, we also evaluated the cancer-related factors tumour type, stage, and treatment.

Functional status was measured with the Katz index of Activities of Daily Living (ADL) (range: 0-6) and the Lawton Instrumental ADL (IADL) scale (range: 0-8 for woman, range: 0-5 for men) $[14,15]$. Dependence in one or more domains for each test was defined as having an impaired test result. Depression was measured using the Geriatric Depression Scale (range: 0-15, cut-off $\geq 5$ ), loneliness with the loneliness scale of De Jong-Gierveld (range: 0-11, cut-off $\geq 3$ ), fatigue with a Visual Analogue Scale (range: 0-10, cut-off $\geq 4$ ), cognitive status with the Mini Mental State Examination (range: 0-30, cut-off $<24)$, and comorbidity with the Charlson Comorbidity Index (CCI) (range: 0-37, cut-off $\geq 1$ ) [16-19]. Nutrition was measured with a new and adapted version of the Mini Nutritional Assessment-short form (range: 0-14, cut-off $\leq 11)$, which is currently being validated by our group [20].

\section{Data analysis}

Firstly, formal and informal care were studied separately. Individual home care services, as specified in our definition of formal care, were studied as well. Finally, we considered formal care and informal care simultaneously. This entails four possible situations at baseline: no care, informal care only, formal care only, and the availability of both formal and informal care. Hence, 16 alternative transitions are possible after one year. Next to transitions to formal care or informal care, we also 
evaluated whether both types of care substitute ('substitution') or complement ('complementarity') each other to better understand the relationship between formal and informal care. Substitution was defined as the sum of transitions from formal to informal care and vice versa. Complementarity was defined as the sum of transitions from no care or (in)formal care only towards combined formal and informal care.

We performed comparative analyses between OCP and two control groups $\mathrm{ONC}$ and MCP at baseline by means of the chi-square test. Changes in care over time were studied by comparing formal and informal care between baseline and one year follow-up within each patient group with the McNemar test and by calculating the percentages of every transition in and between formal and informal care. We set alpha at 0.05 for all analyses to denote statistical significance.

For the second goal of our analysis, logistic regression analyses were conducted to explain the transition of no formal care to formal care in patients with cancer, both OCP and MCP. Separate analyses for OCP and MCP were not conducted due to a small sample size for OCP. Univariate analyses were performed with all predisposing, enabling, and need factors as continuous predictors with the exception of IADL which was analyzed as a dichotomous variable due to the different score range for women and men. In addition, we considered changes of need factors over time by dichotomizing them and identifying changes in categories between baseline and one year follow-up. All analyses were performed using SPSS 23 software (Chicago, IL).

\section{Results}

\section{Study population}

A total of 844 patients, recruited between April 2010 and November 2013, were available for analysis at baseline. At follow-up, data for formal care were also available for a total of 469 patients (56\%) (see Fig. 1). Missing follow-up data were due to death $(2.7 \%$ ONC, $10.6 \%$ OCP, and $6.3 \% \mathrm{MCP}$ ) or to loss of follow-up/refusal (38.7\%, 37.3\%, and 39.4\%). Patient characteristics of OCP and the two control groups are shown in Table 1. Differences in need factors for formal care are found in Table 2. The majority of the patients were female (ONC: 61.3\%, OCP: 69.6\%, MCP: 75.1\%). Compared to ONC, OCP had a worse nutritional status, were less lonely, and had less comorbidity and polypharmacy.

\section{The comparison of formal and informal care at baseline}

Results of the baseline comparisons between OCP and the two control groups are summarized in Table 3. About half of the OCP were users of formal care

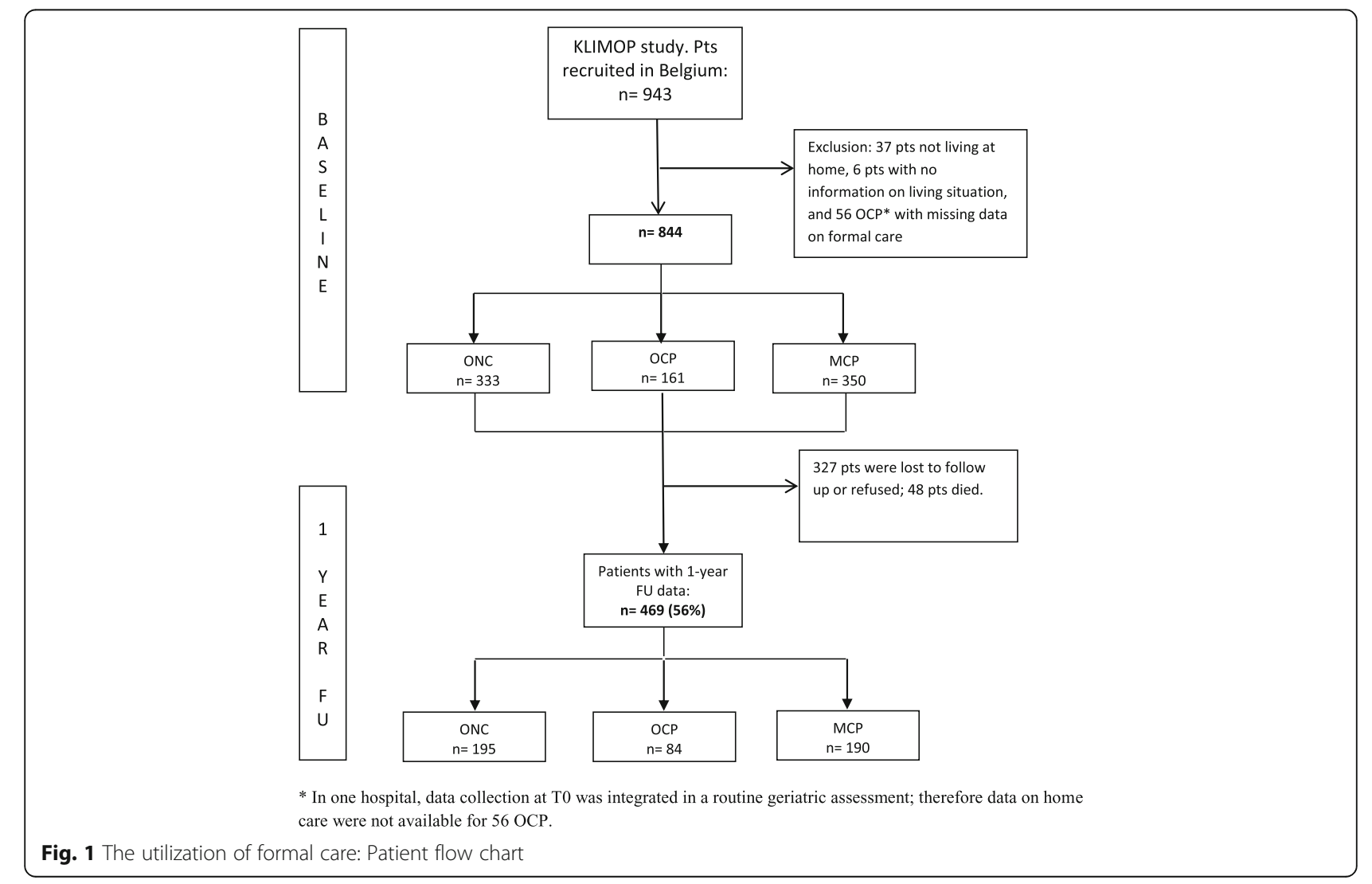


Table 1 Patient characteristics of the three patient groups at baseline

\begin{tabular}{|c|c|c|c|c|c|c|c|c|}
\hline & ONC & & & OCP & & & $\mathrm{MCP}$ & \\
\hline & $n$ & $\%$ & $p$-value & $n$ & $\%$ & $p$-value & $n$ & $\%$ \\
\hline Total $N^{\circ}$ pts & 333 & 100.0 & & 161 & 100.0 & & 350 & 100.0 \\
\hline \multicolumn{9}{|l|}{ Age } \\
\hline Mean (SD) & $78.7(5.7)$ & & & $76.9(5.0)$ & & & $59.8(5.4)$ & \\
\hline Gender & & & 0.07 & & & 0.19 & & \\
\hline Female & 204 & 61.3 & & 112 & 69.6 & & 263 & 75.1 \\
\hline Male & 129 & 38.7 & & 49 & 30.4 & & 87 & 24.9 \\
\hline Living situation & & & 0.75 & & & $<0.001$ & & \\
\hline Alone & 109 & 32.7 & & 55 & 34.2 & & 48 & 13.7 \\
\hline Not alone & 224 & 67.3 & & 106 & 65.8 & & 302 & 86.3 \\
\hline Marital status & & & 0.68 & & & $<0.001$ & & \\
\hline Married/living together & 209 & 62.8 & & 98 & 60.9 & & 285 & 81.4 \\
\hline Unmarried/widow/divorced & 124 & 37.2 & & 63 & 39.1 & & 65 & 18.6 \\
\hline Educational level & $n=328$ & & 0.66 & $n=157$ & & $<0.001$ & $n=344$ & \\
\hline$\leq 14$ years & 94 & 28.7 & & 50 & 31.8 & & 37 & 10.8 \\
\hline $15-19$ years & 150 & 45.7 & & 72 & 45.9 & & 161 & 46.8 \\
\hline$\geq 19$ years & 84 & 25.6 & & 35 & 22.3 & & 146 & 42.4 \\
\hline Tumour type & & & & & & 0.07 & & \\
\hline Breast & & & & 86 & 53.4 & & 217 & 62.0 \\
\hline Gastrointestinal & & & & 69 & 42.9 & & 114 & 32.6 \\
\hline Lung & & & & 6 & 3.7 & & 19 & 5.4 \\
\hline Stage & & & & $n=137$ & & 0.004 & $n=327$ & \\
\hline I & & & & 18 & 13.1 & & 87 & 26.6 \\
\hline$\|$ & & & & 69 & 50.4 & & 121 & 37.0 \\
\hline III & & & & 35 & 25.5 & & 93 & 28.4 \\
\hline IV & & & & 15 & 10.9 & & 26 & 8.0 \\
\hline \multicolumn{9}{|l|}{ Treatment $^{a}$} \\
\hline Surgery ${ }^{b}$ & & & & 132 & 89.8 & 0.77 & 304 & 88.9 \\
\hline Chemotherapy $^{\mathrm{b}}$ & & & & 63 & 43.4 & $<0,001$ & 210 & 61.6 \\
\hline Radiotherapy ${ }^{\mathrm{b}}$ & & & & 71 & 49.3 & $<0,001$ & 232 & 68.0 \\
\hline Hormonal $^{b}$ & & & & 59 & 40.7 & 0.03 & 175 & 51.6 \\
\hline
\end{tabular}

OCP were compared to the two control groups with the chi-square test. $p<0.05$ denotes statistical significance ${ }^{a}$ More than one possibility

${ }^{\mathrm{b}}$ Percentages were calculated on valid cases

(51.6\%). There was no difference with the group ONC (50.2\%), but significantly less MCP (18.0\%) were users.

The analysis of the individual home care services only show a significant difference $(p=0.003)$ for seeking help from a physiotherapist between OCP (3.1\%) and ONC (11.1\%). Compared to MCP, we observed no difference for help from the physiotherapist but OCP made significantly more use for all other home care services. None of the patients made use of adult day care. An overview of the number of home care services per patient at $\mathrm{T} 0$ is shown in Additional file 1. While most MCP received 1 or 2 individual home care services, more than $10 \%$ of the OCP and ONC relied on 3 or more services.

Furthermore, our results showed that OCP (86.0\%) could rely as much on informal care as MCP (85.4\%) and more so than ONC (56.8\%).

When considering both formal and informal care, the distribution of types of care differed in every aspect between OCP and ONC. ONC had a higher proportion (25.4\%) of patients with no care compared to the two cancer cohorts (OCP: 7.0\%, MCP: 11.3\%). MCP had more informal care only (70.7\%) than OCP (42.0\%) while 
Table 2 Need factors for formal care of the three patient groups at baseline

\begin{tabular}{|c|c|c|c|c|c|c|c|c|}
\hline & ONC & & & OCP & & & MCP & \\
\hline & $\bar{n}$ & $\%$ & $p$-value & $\mathrm{n}$ & $\%$ & $p$-value & $\mathrm{n}$ & $\%$ \\
\hline Total $N^{\circ}$ pts & 333 & 100.0 & & 161 & 100.0 & & 350 & 100.0 \\
\hline ADL & & & 0.80 & & & $<0,001$ & & \\
\hline Independent & 184 & 55.3 & & 87 & 54.0 & & 273 & 78.0 \\
\hline Dependent & 149 & 44.7 & & 74 & 46.0 & & 77 & 22.0 \\
\hline IADL & $n=329$ & & 0.55 & $n=160$ & & $<0,001$ & $n=344$ & \\
\hline Independent & 184 & 55.9 & & 94 & 58.8 & & 269 & 78.2 \\
\hline Dependent & 145 & 44.1 & & 66 & 41.3 & & 75 & 21.8 \\
\hline Depression & $n=322$ & & 0.53 & $n=148$ & & 0.34 & $n=322$ & \\
\hline Normal & 276 & 85.7 & & 130 & 87.8 & & 292 & 90.7 \\
\hline Impaired & 46 & 14.3 & & 18 & 12.2 & & 30 & 9.3 \\
\hline Cognition & & & 0.72 & & & 0.01 & & \\
\hline Normal & 292 & 87.7 & & 143 & 88.8 & & 333 & 95.1 \\
\hline Impaired & 41 & 12.3 & & 18 & 11.2 & & 17 & 4.9 \\
\hline Nutrition & $n=280$ & & $<0,001$ & $n=135$ & & 0.45 & $n=320$ & \\
\hline Normal & 229 & 81.8 & & 48 & 35.6 & & 102 & 31.9 \\
\hline At risk/malnourished & 51 & 18.2 & & 87 & 64.4 & & 218 & 68.1 \\
\hline Loneliness & $n=318$ & & 0.004 & $n=138$ & & 0.03 & $n=322$ & \\
\hline Not lonely & 178 & 56.0 & & 97 & 70.3 & & 257 & 79.8 \\
\hline Lonely & 140 & 44.0 & & 41 & 29.7 & & 65 & 20.2 \\
\hline Fatigue & $n=331$ & & 0.19 & $n=149$ & & 0.18 & $n=336$ & \\
\hline No fatigue & 150 & 45.3 & & 58 & 38.9 & & 153 & 45.5 \\
\hline Fatigue & 181 & 54.7 & & 91 & 61.1 & & 183 & 54.5 \\
\hline Polypharmacy & & & $<0,001$ & & & $<0,001$ & & \\
\hline$<5$ drugs & 150 & 45.0 & & 109 & 67.7 & & 305 & 87.1 \\
\hline$\geq 5$ drugs & 183 & 55.0 & & 52 & 32.3 & & 45 & 12.9 \\
\hline Comorbidity & $n=326$ & & $<0,001$ & $n=148$ & & $<0.001$ & $n=339$ & \\
\hline $\mathrm{CCl} O$ & 145 & 44.5 & & 92 & 62.2 & & 269 & 79.4 \\
\hline $\mathrm{CCl} \geq 1$ & 181 & 55.5 & & 56 & 37.8 & & 70 & 20.6 \\
\hline
\end{tabular}

OCP were compared to the two control groups with the chi-square test. $p<0.05$ denotes statistical significance

OCP relied more on both types of care $(43.9 \%)$ than MCP (14.6\%).

\section{The comparison of formal and informal care between T0 and $\mathrm{T} 1$}

Table 4 presents the differences in care between T0 and $\mathrm{T} 1$ in the three patients groups. In the group ONC, there was overall an increase of formal care at T1. No other differences were observed.

In the group OCP, there was overall an increase of formal care at T1. However this difference was not statistically significant $(p=0.06)$. At the level of individual home care services, significantly more patients saw a physiotherapist after one year (from $3.1 \%$ to $19.0 \%$, $p=0.01$ ). There was no significant difference in informal care between $\mathrm{T} 0$ and $\mathrm{T} 1(p=0.65)$. However, when considering both formal and informal care, fewer patients received only informal care $(\mathrm{p}=0.01)$ at $\mathrm{T} 1$.

In the group $\mathrm{MCP}$, there was overall an increase of formal care at T1. Increased help from a home nurse (from $4.0 \%$ to $11.1 \%$ ), cleaning help (from $14.0 \%$ to $23.2 \%$ ), and a physiotherapist (from $4.0 \%$ to $17.9 \%$ ) was reported. From the patients who received physiotherapy, $71.4 \%$ and $94.1 \%$ had breast cancer at respectively $\mathrm{T} 0$ and $\mathrm{T} 1$. Informal care decreased at T1 (from 85.4\% to 75.7\%). When considering both formal and informal care, fewer patients received only informal care and more patients received both formal and informal care.

\section{Transitions in formal and informal care after one year}

Transitions in formal and informal care were analyzed separately in Table 5 . There was a significant difference 
Table 3 The comparison of formal and informal care at baseline between OCP and two control groups

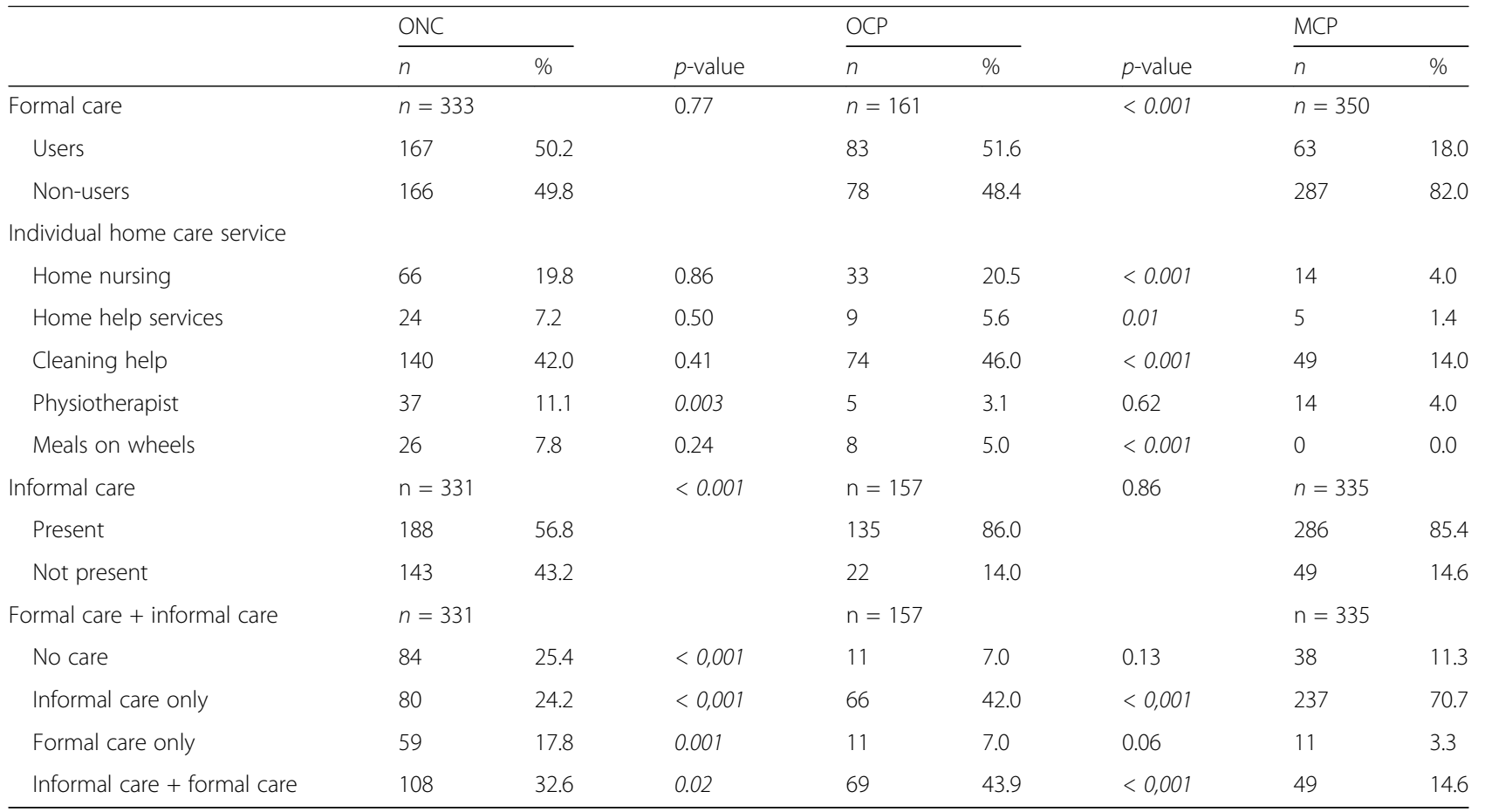

OCP were compared to the two control groups with the chi-square test. $p<0.05$ denotes statistical significance

Table 4 The comparison of formal and informal care between T0 and T1 in each patient group

\begin{tabular}{|c|c|c|c|c|c|c|c|c|c|c|c|c|c|c|c|}
\hline & \multicolumn{4}{|l|}{ ONC } & \multirow[b]{3}{*}{$p$-value } & \multicolumn{4}{|c|}{ OCP } & \multirow[b]{3}{*}{$p$-value } & \multicolumn{4}{|l|}{ MCP } & \multirow[b]{3}{*}{$p$-value } \\
\hline & \multicolumn{2}{|l|}{ T0 } & \multicolumn{2}{|l|}{$\mathrm{T} 1$} & & \multicolumn{2}{|l|}{ T0 } & \multicolumn{2}{|l|}{ T1 } & & \multicolumn{2}{|l|}{ T0 } & \multicolumn{2}{|l|}{ T1 } & \\
\hline & $n$ & $\%$ & $n$ & $\%$ & & $\mathrm{n}$ & $\%$ & $n$ & $\%$ & & $n$ & $\%$ & $n$ & $\%$ & \\
\hline Formal care & \multicolumn{2}{|c|}{$n=333$} & \multicolumn{2}{|c|}{$n=195$} & 0.03 & \multicolumn{2}{|c|}{$n=161$} & \multicolumn{2}{|c|}{$n=84$} & 0.06 & \multicolumn{2}{|c|}{$n=350$} & \multicolumn{2}{|c|}{$n=190$} & $<0,001$ \\
\hline Users & 167 & 50.2 & 110 & 56.4 & & 83 & 51.6 & 55 & 65.5 & & 63 & 18.0 & 77 & 40.5 & \\
\hline Non-users & 166 & 49.8 & 85 & 43.6 & & 78 & 48.4 & 29 & 34.5 & & 287 & 82.0 & 113 & 59.5 & \\
\hline \multicolumn{16}{|l|}{ Individual home care service } \\
\hline Home nursing & 66 & 19.8 & 42 & 21.5 & 0.08 & 33 & 20.5 & 20 & 23.8 & 1.00 & 14 & 4.0 & 21 & 11.1 & 0.01 \\
\hline Home help services & 24 & 7.2 & 9 & 4.6 & 0.21 & 9 & 5.6 & 6 & 7.1 & 0.73 & 5 & 1.4 & 3 & 1.6 & 1.00 \\
\hline Cleaning help & 140 & 42.0 & 92 & 47.2 & 0.29 & 74 & 46.0 & 43 & 51.2 & 1.00 & 49 & 14.0 & 44 & 23.2 & 0.02 \\
\hline Physiotherapy & 37 & 11.1 & 23 & 11.8 & 0.66 & 5 & 3.1 & 16 & 19.0 & 0.01 & 14 & 4.0 & 34 & 17.9 & $<0,001$ \\
\hline Meals on wheels & 26 & 7.8 & 11 & 5.6 & 0.11 & 8 & 5.0 & 3 & 3.6 & 1.00 & 0 & 0.0 & 1 & 0.5 & 1.00 \\
\hline Informal care & \multicolumn{2}{|c|}{$n=331$} & \multicolumn{2}{|c|}{$n=191$} & 1.00 & \multicolumn{2}{|c|}{$n=157$} & \multicolumn{2}{|c|}{$n=80$} & 0.65 & \multicolumn{2}{|c|}{$n=335$} & \multicolumn{2}{|c|}{$n=185$} & 0.03 \\
\hline Present & 188 & 56.8 & 103 & 53.9 & & 135 & 86.0 & 63 & 78.8 & & 286 & 85.4 & 140 & 75.7 & \\
\hline Not present & 143 & 43.2 & 88 & 46.1 & & 22 & 14.0 & 17 & 21.3 & & 49 & 14.6 & 45 & 24.3 & \\
\hline Formal care + informal care & \multicolumn{2}{|c|}{$n=331$} & \multicolumn{2}{|c|}{$n=191$} & & \multicolumn{2}{|c|}{$n=157$} & \multicolumn{2}{|c|}{$\mathrm{n}=80$} & & \multicolumn{2}{|c|}{$n=335$} & \multicolumn{2}{|c|}{$n=185$} & \\
\hline No care & 84 & 25.4 & 40 & 20.9 & 0.10 & 11 & 7.0 & 7 & 8.8 & 1.00 & 38 & 11.3 & 30 & 16.2 & 0.24 \\
\hline Informal care only & 80 & 24.2 & 43 & 22.5 & 1.00 & 66 & 42.0 & 19 & 23.8 & 0.01 & 237 & 70.7 & 79 & 42.7 & $<0,001$ \\
\hline Formal care only & 59 & 17.8 & 48 & 25.1 & 0.07 & 11 & 7.0 & 10 & 12.5 & 0.79 & 11 & 3.3 & 15 & 8.1 & 0.08 \\
\hline Informal care + formal care & 108 & 32.6 & 60 & 31.4 & 1.00 & 69 & 43.9 & 44 & 55.0 & 0.06 & 49 & 14.6 & 61 & 33.0 & $<0,001$ \\
\hline
\end{tabular}


Table 5 Transitions in formal and informal home care analyzed separately

\begin{tabular}{|c|c|c|c|c|c|c|c|c|}
\hline & \multicolumn{2}{|c|}{ ONC } & \multirow[b]{2}{*}{$p$-value } & \multicolumn{2}{|c|}{$\underline{\mathrm{OCP}}$} & \multirow[b]{2}{*}{$p$-value } & \multicolumn{2}{|c|}{ MCP } \\
\hline & $n$ & $\%$ & & $n$ & $\%$ & & $n$ & $\%$ \\
\hline & \multicolumn{8}{|c|}{ Formal care } \\
\hline Transition & \multicolumn{3}{|c|}{$n=195$} & \multicolumn{3}{|c|}{$n=84$} & \multicolumn{2}{|c|}{$n=190$} \\
\hline No formal care at T0 and T1 & 80 & 41.0 & 0.05 & 24 & 28.6 & $<0,001$ & 101 & 53.2 \\
\hline Formal care at $\mathrm{T} 0$ and $\mathrm{T} 1$ & 94 & 48.2 & 0.93 & 41 & 48.8 & $<0,001$ & 26 & 13.7 \\
\hline No formal care - > Formal care & 16 & 8.2 & 0.04 & 14 & 16.7 & 0.07 & 51 & 26.8 \\
\hline \multirow[t]{2}{*}{ Formal care $->$ No formal care } & 5 & 2.6 & 0.16 & 5 & 6.0 & 0.91 & 12 & 6.3 \\
\hline & \multicolumn{8}{|c|}{ Informal care } \\
\hline Transition & \multicolumn{3}{|c|}{$n=190$} & \multicolumn{3}{|c|}{$n=79$} & \multicolumn{2}{|c|}{$n=178$} \\
\hline No informal care at T0 and T1 & 62 & 32.6 & $<0,001$ & 6 & 7.6 & 0.55 & 10 & 5.6 \\
\hline Informal care at $\mathrm{T} 0$ and $\mathrm{T} 1$ & 79 & 41.6 & $<0,001$ & 54 & 68.4 & 0.88 & 120 & 67.4 \\
\hline No informal care $->$ Informal care & 24 & 12.6 & 0.56 & 8 & 10.1 & 0.77 & 16 & 9.0 \\
\hline Informal care $->$ No informal care & 25 & 13.2 & 0.87 & 11 & 13.9 & 0.42 & 32 & 18.0 \\
\hline
\end{tabular}

OCP were compared to the two control groups with the chi-square test. $p<0.05$ denotes statistical significance

in the transition from no formal care to formal care between OCP and the two control groups. For the group OCP, $16.7 \%$ made this transition compared to $8.2 \%$ ONC $(p=0.04)$ and $26.8 \% \mathrm{MCP}(p=0.07)$. For the transition from formal care to no formal care, a similar proportion OCP (6.0\%) stopped formal care compared to MCP (6.3\%) after one year. Only a small proportion of ONC $(2.6 \%$, $p=0.16)$ stopped relying upon formal care.

Transitions in informal care were similar between OCP and the two control groups. In the groups ONC, OCP, and MCP respectively $12.6 \%, 10.1 \%$, and $9.0 \%$ made a transition to informal care at $\mathrm{T} 1$ while respectively $13.2 \%, 13.9 \%$, and 18.0 stopped relying on informal care.

Transitions considering the availability of formal care and informal care simultaneously are summarized in Additional file 2. Transitions in care, from any type, were observed in $\mathrm{ONC}$, OCP, and MCP in respectively $33.2 \%, 39.2 \%$, and $49.4 \%$ of the patients. The analysis of substitution and complementarity of care shows that in $5.1 \%$ of OCP formal and informal care substitute each other, while in $17.7 \%$ both types of care complement each other at T1. Results for the control groups are shown in Table 6.

Table 6 Substitution and complementarity of formal and informal care

\begin{tabular}{|c|c|c|c|c|c|c|c|c|}
\hline & \multicolumn{2}{|c|}{ ONC } & \multirow[b]{2}{*}{$p$-value } & \multicolumn{2}{|c|}{ OCP } & \multirow[b]{2}{*}{$p$-value } & \multicolumn{2}{|c|}{ MCP } \\
\hline & $n$ & $\%$ & & $n$ & $\%$ & & $n$ & $\%$ \\
\hline Transition & \multicolumn{2}{|c|}{$n=190$} & & \multicolumn{2}{|c|}{$n=79$} & & \multicolumn{2}{|c|}{$n=178$} \\
\hline Substitution & 0 & .0 & 0.07 & 4 & 5.1 & 1.0 & 11 & 6.2 \\
\hline Complementarity & 19 & 10.0 & 0.08 & 14 & 17.7 & 0.44 & 39 & 21.9 \\
\hline
\end{tabular}

OCP were compared to the two control groups with the chi-square test or fisher's exact test where appropriate. $p<0.05$ denotes

statistical significance
Predictors of the transition no formal care to formal care after a cancer diagnosis

The studied sample for this analysis consisted of a total of 190 patients with cancer (20.0\% OCP), of which 65 made the transition from no formal care to formal care. Significant predictors in univariate analysis are shown in Table 7. Next to a higher value for the need factors fatigue and polypharmacy, certain changes (or the lack of) in $\mathrm{ADL}$, IADL, depression, fatigue, and polypharmacy were predictive for a transition towards formal home care. Furthermore, a worse cancer stage and having received chemotherapy or radiotherapy were predictive as well. Factors that were not predictive included predisposing variables, ADL, IADL, informal care, and belonging to the group OCP or MCP.

\section{Discussion}

Transitions in home care depend on the situation. A diagnosis of cancer might be considered a situation of greater need for care and as such we observed transitions in formal and informal care in ONC, OCP, and MCP in respectively $33.2 \%, 39.2 \%$, and $49.4 \%$ after one year. Our results also showed an expected increase in new users of formal care in cancer patients: $16.7 \%$ for OCP, $26.8 \%$ for MCP compared to $8.2 \%$ for ONC. However, at baseline, i.e. shortly after diagnosis, some important differences were already observed between the patient groups in terms of care but also in patient characteristics. While many differences between OCP and $\mathrm{MCP}$ can be explained due to age-related factors, some differences between OCP and ONC were less obvious. OCP had a lower comorbidity burden and polypharmacy. This can partially be explained by a referral bias for OCP; the frailest patients are not always referred to the oncologist. OCP reported to be less lonely despite 
Table 7 Predictors of the transition no formal to formal care 1 year after a cancer diagnosis (OCP and MCP combined, $n=190$ )

\begin{tabular}{|c|c|c|c|}
\hline \multirow{3}{*}{ Need factors } & \multicolumn{3}{|c|}{ Univariate $^{a}$} \\
\hline & \multirow{2}{*}{$\overline{\mathrm{OR}}$} & \multirow[t]{2}{*}{$95 \% \mathrm{Cl}$} & \multirow[t]{2}{*}{$p$-value } \\
\hline & & & \\
\hline Fatigue & 1.24 & $1,09-1,41$ & 0.001 \\
\hline Polypharmacy & 1.18 & $1,01-1,38$ & 0.04 \\
\hline \multicolumn{4}{|l|}{ Cancer-related factors } \\
\hline Stage & & & 0.09 \\
\hline I & ref & & \\
\hline$\|$ & 2.01 & $0,85-4,78$ & 0.11 \\
\hline III & 2.67 & $1,02-6,96$ & 0.05 \\
\hline IV & 5.93 & $1,18-29,68$ & 0.03 \\
\hline Chemotherapy & 2.21 & $1,17-4,19$ & 0.02 \\
\hline Radiotherapy & 2.38 & $1,19-4,77$ & 0.02 \\
\hline \multicolumn{4}{|l|}{ Changes in need factors } \\
\hline $\mathrm{ADL}$ & & & 0.01 \\
\hline persistently independent & ref & & \\
\hline became indepedent & 0.93 & $0,27-3,13$ & 0.90 \\
\hline became dependent & 3.19 & $1,55-6,54$ & 0.002 \\
\hline persistently dependent & 0.85 & $0,28-2,54$ & 0.77 \\
\hline IADL & & & 0.04 \\
\hline persistently independent & ref & & \\
\hline became indepedent & 1.81 & $0,60-5,50$ & 0.29 \\
\hline became dependent & 2.86 & $1,36-6,04$ & 0.01 \\
\hline persistently dependent & 2.04 & $0,66-6,33$ & 0.22 \\
\hline Depression & & & 0.06 \\
\hline persistently normal & ref & & \\
\hline became normal & 2.53 & $0,77-8,32$ & 0.13 \\
\hline became depressed & 3.03 & $1,21-7,60$ & 0.02 \\
\hline persistently depressed & 2.53 & $0,34-18,59$ & 0.36 \\
\hline Fatigue & & & 0.003 \\
\hline persistently normal & ref & & \\
\hline became normal & 6.00 & $1,55-23,19$ & 0.01 \\
\hline became impaired & 4.00 & $1,19-13,42$ & 0.03 \\
\hline persistently impaired & 8.27 & $2,61-26,22$ & $<0,001$ \\
\hline Polypharmacy & & & 0.04 \\
\hline persistently normal & ref & & \\
\hline became normal & 2.51 & $0,60-10,52$ & 0.21 \\
\hline became impaired & 2.72 & $1,15-6,46$ & 0.02 \\
\hline persistently impaired & 2.93 & $0,93-9,25$ & 0.07 \\
\hline
\end{tabular}

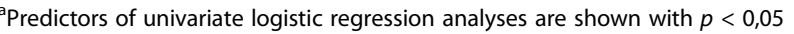

no difference in marital status or living situation. Previously, we already showed that at baseline fewer patients with cancer had feelings of loneliness than ONC and that after one year the proportion of cancer patients with loneliness increased significantly reaching the levels of ONC [11]. Our current analysis might explain these differences in loneliness by looking at the received informal care. More patients with cancer relied on informal care compared to ONC at baseline. This care was likely provided only recently around the time the patient was informed about a cancer diagnosis which could explain the difference in baseline loneliness between patients with cancer and ONC. Furthermore, informal care decreased after one year in both cancer cohorts, although not significantly in OCP, which could contribute to the increase in loneliness in both cancer cohorts. It is to be expected that newly diagnosed patients receive much help and support from their environment at first but less so after completing their treatment and this might have an impact on feelings of loneliness, an important measure of well-being.

The analysis of the individual home care services showed that cleaning help was clearly the most used service in the three patient groups. In this regard, we note that we did not document whether the use of this service was related to any health-related issues. Furthermore, at baseline fewer cancer patients visited the physiotherapist compared to ONC. However, after one year a strong increase in physiotherapy was observed in both cancer cohorts, mainly in patients with breast cancer. This might be related to lymphoedema following breast cancer surgery or radiotherapy. While, besides physiotherapy, no other changes were observed after one year in OCP, MCP made more use of home nursing and cleaning help next to an increase in physiotherapy. A possible explanation for this is that due to lymphoedema, MCP are less able to do household tasks like cleaning or are advised to limit the strenuous use of their arm. Also, an important proportion of patients with cancer will have had an intestinal stoma. These patients, OCP likely more than MCP, might rely upon home nursing for stoma care. These increases of home nursing and cleaning help after one year in MCP are however not observed in OCP. However, the baseline percentages for both home care services are already high in OCP and new tasks might have been covered by the already available care in this group.

About half of the OCP and ONC received formal care at baseline. This formal care was more often in combination with informal care in OCP than in ONC. When considering both formal care and informal care after one year, the main trend observed in both cancer cohorts, in contrast to $\mathrm{ONC}$, is the decrease in the number of patients who rely on informal care only and the increase in patients with formal care whether or not with informal care. This distinction between ONC and cancer patients can be explained by the dynamics in informal care in cancer patients as discussed previously and by the expected increased need for formal care in cancer patients 
which was quantified in this study. Another important observation is the lack of any change in the proportion of patients with no care whatsoever in the three patient groups.

Several studies in the general population suggest that formal and informal care complement rather than substitute each other [6-8]. This is also shown in our three patient groups. Our rates for substitution and complementarity for ONC are similar with other reports for the general population in Belgium [8]. These rates are however higher in our studied cancer cohorts, particularly for complementarity. In the context of cancer, more technical skills (e.g. injections, stoma care, and physiotherapy) for care might be required and this care will complement rather than substitute informal care. Several care models have been proposed for the general population [21]. For patients diagnosed with cancer, formal and informal care might be better explained with a complementarity and task-specific model.

Our results show different dynamics in care between older patients with and without cancer but also between $\mathrm{OCP}$ and $\mathrm{MCP}$. International guidelines recommend the implementation of a geriatric assessment in OCP to guide treatment decisions in routine oncology practice [22]. This assessment will lead to the necessary referrals for many patients with cancer [23]. In contrast to the general population, many $\mathrm{OCP}$ will be seen by a social worker in the hospital which will also drive changes in formal care. In this regard, we mention the Belgian implementation of the InterRAI instruments (BelRAI) which is an ambitious web-based comprehensive assessment system to improve the quality and continuity of care across different health care settings, including home care [24-26]. It is advisable to harmonize recommendations in geriatric oncology to implement geriatric assessment in daily practice with efforts like the BelRAI for the general population at a national level for future policies.

For the second goal of our study, we analyzed predictors for the transition from no formal care to formal care one year after a cancer diagnosis. Functional status, the availability of informal care, and dispositional factors did not predict the transition towards formal care in patients with cancer. Cancer-related factors, i.e. more advanced disease or a more extensive treatment, and the related worsening of need factors (more than their baseline values) were significant predictors. In contrast, an analogous analysis on ONC showed that only developing a nutritional impairment predicted a transition towards formal care (data not reported). Our results show that the first year after a cancer diagnosis is an important time to follow-up on the patients' needs for home care at different time points during the disease trajectory. More longitudinal research is needed to determine to what degree a cancer diagnosis is a turning point towards more formal care or whether the increased use of formal care is more of a temporary nature. Another evolution to follow in the future relevant to homecare, is the parenteral administration of cancer treatments at home. The first pilot projects in this regard have been started in Belgium.

When interpreting our results, some considerations should be made. The study of both formal and informal care is a strength of this study, however the collection of more detailed information on informal care would have been beneficial for our analysis. Many patients were lost to follow-up (LTFU), i.e. a total of $38.7 \%$ when not considering the patients that died (5.7\%). Additional analyses (Additional file 3) show no major baseline differences between LTFU patients who were alive and patients with one-year follow-up data. LTFU patients had less cleaning help and more informal care only, no other differences were observed for home care. Furthermore, there was a similar proportion of LTFU patients (excluding deaths) in the three patient groups. Another point to consider is that our results apply for Belgium, a well-developed welfare state with well-developed formal services. A lot has been written in the home care literature, which focuses on the general population, about the different dynamics of formal and informal care between European countries, about the influence of the strength of family ties, and a north-south gradient [8]. To our knowledge, there are no similar studies to which we can compare our results with that evaluate changes in both formal and informal care after a cancer diagnosis.

\section{Conclusions}

A cancer diagnosis has a different impact on the use of formal and informal care than ageing as such. The first year after a cancer diagnosis is an important time to follow-up on the patients' needs for home care.

\section{Additional files}

Additional file 1: Amount of home care services per patient at baseline An overview of the number of home care services per patient at T0 is shown for the three patient groups. (XLSX $16 \mathrm{~kb}$ )

Additional file 2: Individual transitions between formal care and informal care. Transitions considering the availability of both formal care and informal care are summarized for the three patient groups. (XLSX $13 \mathrm{~kb}$ )

Additional file 3: Baseline comparisons for care in patients with and without missing 1-year data. Formal care and informal care are compared between patients included in the longitudinal analyses and patients that were lost to follow-up after 1 year. Separate comparisons were made with patients who were lost to follow-up and alive and with patients who had died after 1 year. (XLSX $14 \mathrm{~kb}$ )

Additional file 4: Database. The database on which the current analysis was conducted is included. (SAV $57 \mathrm{~kb}$ )

\section{Abbreviations}

ADL: Activities of daily living; CCl: Charlson comorbidity index; IADL: Instrumental activities of daily living; LTFU: Lost to follow-up; MCP: Middle-aged patients with 
cancer; OCP: Older patients with cancer; ONC: Older primary care patients without cancer

\section{Acknowledgements}

This work was supported by the European Union/Interreg IV Grensregio Vlaanderen - Nederland (IVA-VLANED-3.46) and "de Vlaamse Liga tegen Kanker" (Flemish League against Cancer) (10482). This study was only possible thanks to the participating patients, physicians, and nurses.

\section{Funding}

The European Union/Interreg IV Grensregio Vlaanderen - Nederland (IVA-VLANED-3.46), and "De Vlaamse Liga tegen Kanker" (Flemish League against Cancer) (10482), supported the Klimop study. The authors had complete authority over design, execution, analysis, and interpretation of the study.

\section{Availability of data and materials}

The dataset supporting the conclusions of this article is included as an additional file within the article (Additional file 4).

\section{Authors' Contributions}

This study was designed by $A B, F B, M v d A$, whereas the umbrella study KLIMOP was designed and set up by FM, MvdA, LD, PB and HW. Data collection was performed by all authors. AB, FB, TdB, MvdA drafted the manuscript, which was commented by all authors. Statistical analysis was performed by $A B$ and discussed with $F B, M v d A$, and TdB. All authors read and approved the final manuscript.

\section{Ethics approval and consent to participate}

The study protocol was approved by the Ethical Review Board of KU Leuven and UZ Leuven (S52097-ML6279). All patients signed informed consent prior to study entry.

\section{Consent for publication}

Not applicable.

\section{Competing interests}

The authors declare that they have no competing interests.

\section{Publisher's Note}

Springer Nature remains neutral with regard to jurisdictional claims in published maps and institutional affiliations.

\section{Author details}

${ }^{1}$ Department of Oncology, ZNA Middelheim, Antwerp, Belgium. ${ }^{2}$ Academic Centre for General Practice/ Department of Public Health and Primary Care, KU Leuven, Leuven, Belgium. ${ }^{3}$ Department of Family Medicine, School CAPHRI, Maastricht University, Maastricht, The Netherlands. ${ }^{4}$ Department of General Practice, University of Queensland, Brisbane, Australia. ${ }^{5}$ Limburgs Oncologisch centrum, Jessa hospital, Hasselt, Belgium. ${ }^{6}$ Department of General Medical Oncology, University hospitals Leuven, Leuven, Belgium.

\section{Received: 6 September 2016 Accepted: 4 September 2017}

\section{Published online: 12 September 2017}

\section{References}

1. Sermeus W, Pirson M, Paquay L, Pacolet J, Falez F, Stordeur S, Leys M. Financing of home nursing in Belgium - KCE report 2010.

2. Kempen Gl, Suurmeijer TP. Factors influencing professional home care utilization among the elderly. Soc Sci Med. 1991;32(1):77-81.

3. Frederiks CM, te Wierik MJ, van Rossum HJ, Visser AP, Volovics A, Sturmans F. Why do elderly people seek professional home care? Methodologies compared J Community Health. 1992;17(3):131-41.

4. Kemper P. The use of formal and informal home care by the disabled elderly. Health Serv Res. 1992;27:421-49.

5. Kadushin G. Home health care utilization: a review of the research for social work. Health Soc Work. 2004;29(3):219-44.

6. Geerlings S, Pot AM, Twisk JWR, Deeg DJH. Predicting transitions in the use of informal and professional care by older adults. Ageing Soc. 2005;25(1):111-30.
7. Bolin $K$, Lindgren B, Lundborg P. Informal and formal care among single-living elderly in Europe. Health Econ. 2008;17(3):393-409.

8. Geerts J, Van den Bosch K. Transitions in formal and informal care utilization amongst older Europeans: the impact of national contexts. European Journal of Ageing. 2012;9(1):27-37.

9. Suanet B. Broese van Groenou M, van Tilburg T. Informal and formal home-care use among older adults in Europe: can cross-national differences be explained by societal context and composition? Ageing Soc. 2012;32(3):491-515.

10. Deckx L, van Abbema D, van den Akker M, van den Broeke C, van Driel M, Bulens $\mathrm{P}$, et al. A cohort study on the evolution of psychosocial problems in older patients with breast or colorectal cancer: comparison with younger cancer patients and older primary care patients without cancer. BMC Geriatr. 2015;15:79.

11. Deckx L, van den Akker $M$, van Driel $M$, Bulens $P$, van Abbema $D$, Tjan-Heijnen $V$, et al. Loneliness in patients with cancer: the first year after cancer diagnosis. Psychooncology. 2015;24(11):1521-8.

12. Deckx L, van Abbema D, Nelissen $K$, Daniels L, Stinissen $P$, Bulens $P$, et al. Study protocol of KLIMOP: a cohort study on the wellbeing of older cancer patients in Belgium and the Netherlands. BMC Public Health. 2011;11:825.

13. Andersen R. Revisiting the behavioral model and access to medical care: does it matter? J Health Soc Behav. 1995:36(1):1-10.

14. Katz S, Ford AB, Moskowitz RW, Jackson BA, Jaffe MW. Studies of illness in the aged - the index of Adl - a standardized measure of biological and psychosocial function. Jama-Journal of the American Medical Association. 1963:185(12):914-9.

15. Lawton MP, Brody EM. Assessment of older people - self-maintaining and instrumental activities of daily living. Gerontologist. 1969;9(3P1):179-\&.

16. Yesavage JA, Brink TL, Rose TL, Lum O, Huang V, Adey M, Leirer VO. Development and validation of a geriatric depression screening scale : a preliminary report. J Psychiatr Res. 1982;17:37-49.

17. De Jong-Gierveld J, Kamphuis F. The development of a Rasch-type loneliness scale. Appl Psychol Meas. 1985:9:289-99.

18. Folstein MF, Folstein SE, McHugh PR. "Mini-mental state". A practical method for grading the cognitive state of patients for the clinician. J Psychiatr Res 1975;12(3):189-198.

19. Charlson ME, Pompei $P$, Ales KL, Mackenzie CR. A new method of classifying prognostic co-morbidity in longitudinal-studies - development and validation. J Chronic Dis. 1987;40(5):373-83.

20. Rubenstein LZ, Harker JO, Salvà A, et al. Screening for undernutrition in geriatric practice: developing the short-form mini-nutritional assessment (MNA-SF). J Gerontol A Biol Sci Med Sci. 2001;56:M366-72.

21. Lyons KS, Zarit SH. Formal and informal support: the great divide. Int J Geriatr Psychiatry. 1999;14(3):183-92.

22. Wildiers $H$, Heeren P, Puts M, Topinkova E, Janssen-Heijnen ML, Extermann M, et al. International Society of Geriatric Oncology Consensus on geriatric assessment in older patients with cancer. J Clin Oncol. 2014;32(24):2595-603.

23. Baitar A, Kenis C, Moor R, Decoster L, Luce S, Bron D, et al. Implementation of geriatric assessment-based recommendations in older patients with cancer: a multicentre prospective study. J Geriatr Oncol. 2015;6(5):401-10.

24. Buntinx F, Falez F, Swine C, Ylieff M, Closon MC, De Lepeleire J. Interface: rapport 2003. Leuven-Brussel: De organisatie en de financiering van een grensoverschrijdend zorgaanbod in de ouderenzorg/Organisation et financement offre de soins transinstitutionnelle secteur soins aux personnes agée; 2003.

25. De lepeleire J, Falez F, Swine C, Ylieff M, Pepersack T, Buntinx F. Interface: rapport 2005. Leuven-Brussel: De organisatie en de financiering van een grensoverschrijdend zorgaanbod in de ouderenzorg/Organisation et financement offre de soins transinstitutionnelle secteur soins aux personnes agées; 2005.

26. Vanneste D, Vermeulen B, Declerq A. Healthcare professionals' acceptance of BelRAl, a web-based system enabling person-centred recording and data sharing across care settings with interRAl instruments: a UTAUT analysis. BMC Med Inform Decis Mak. 2013:13-129. 